\title{
Engineering of megapolis public passenger transport logistics system from the standpoint of ecosystem- based approach
}

\author{
Tatiana Shulzhenko \\ Department of Logistics and Supply \\ Chain Management \\ Saint-Petersburg State University of \\ Economics \\ Saint-Petersburg, Russia \\ shul-tatiana@yandex.ru
}

\author{
Oleg Badokin \\ Scientific and educational center \\ «Logistics» \\ Saint-Petersburg State University of \\ Economics \\ Saint-Petersburg, Russia \\ olegbadokin@gmail.com
}

\author{
Andrey Zhuk \\ Department of Logistics and Supply \\ Chain Management \\ Saint-Petersburg State University of \\ Economics \\ Saint-Petersburg, Russia \\ zhuk_ae@outlook.com
}

\begin{abstract}
Modern stage of development of public transport systems in large cities is bearing the hallmarks of bifurcational period of developing under the impact of a number of factors to which we can refer emerging of new sharing-based forms of mobility, digital platforms, sophistication and customization of customers requirements put forward to services provided. Potential outcomes are associated with implementation of one of scenarios of further city public passenger transport (hereinafter referred to as "PPT") system development, namely: evolutionary development of existing city PPT logistics system; "quality leap" towards PPT ecosystem engineering on the basis of (i) customer centricity, (ii) improvement of subsystems integratedness level and (iii) activization of using the cuttingedge transportation and management technologies). However, transition to PPT ecosystem-based organization is associated with serious reformation of existing management system whereupon it is required to define (i) expediency of such transition and (ii) composition and boundaries of city PPT ecosystem. The present paper demonstrates methodological tool intended to substantiate the decision to fulfill transition to ecosystem-based PPT organization on the principles of valuebased approach which is envisaging the use of comparative assessment of the level of added value formed by (i) each of city PPT logistic system elements and (ii) anticipated level of customers satisfaction by services provided by the system under study.
\end{abstract}

Keywords - public passenger transport, logistics system, ecosystem, added value.

\section{INTRODUCTION}

System of public passenger transport (PPT) is playing a particular role in prospective economic, social and spatial development of city environment being its essential and one of the most important components. At the same time, modern PPT systems are being considerably affected by numerous factors to which emerging new forms of sharing-based mobility, digital platforms, sophistication and customization of customers requirements put forward to services provided may be referred. In its turn, spontaneous appearing and advancing of new forms of citizens' mobility is stipulated by the satisfaction of increasingly complicating consumers' demands put forward to transportation and accompanying services to which PPT system is not always ready and which fact is impeding its dynamic development. In the course of further PPT system development in order to maintain the system's competitiveness, economic efficiency and sustainability its customer centricity feature should be brought to the forefront and this, generally speaking, is in line with logistic approach methodology used in PPT system management.

However, according to [1], classical model of logistics system is not sufficiently complying with increasingly growing client centricity demands and services complicacy (inter alia, from the viewpoint of their technological effectiveness) which fact, in turn, is causing the necessity to expand resource base for services provision through integration of new elements into PPT logistics system structure. Complicacy of formation and further management of such structures is explained by their numerosity, multiformity as well as variability of inter-linkages between their elements. Attempts to find adequate model intended to describe the system which is integrating structural features under consideration give grounds to address the potential of evolutionary economic theory [2-6] aiming to solve the problem of transformation of PPT logistics system organization forms without sacrificing the fullfledged logistic management tooling and, in particular, to consider the PPT logistics ecosystem in capacity of potential model.

Retrieval of essential characteristics of city PPT ecosystem defines specific features of ecosystem management, in particular, management methods applied, correlation between management and self-management methods (system self-organization), ecosystem boundaries, i.e. composition of ecosystem's manageable elements, that, in turn, results in serious reformation of entire management system of the city. Therefore, issue regarding expediency of transition to ecosystem-based approach in the city PPT system organization becomes essentially important and thus defines the purpose of the forwarded article. Closely related issue is to identify composition and structure of the city PPT ecosystem characterized by potentially wide range of elements accompanied by absence of their selection principle which makes elaborating of tool allowing to identify ecosystem's structural characteristics a crucial task.

\section{MATERIALS AND METHODS}

\section{A. Formation of megapolis PPT ecosystem structure}

Solving of issues associated with elaboration of methodological fundamentals of PPT system engineering require revision of existing conceptual views relating to the system under research which were formed on the basis of classical model of PPT logistics system represented in [7- 
15]. Despite material authors' consent in regard of general characteristics of logistic system under research there are certain argumentative issues in respect of its structure. In particular, L.B. Mirotin [7] is using the definition "regional logistics system of the public transport" (hereafter RLSPT) presenting it as totality of subject and object of the logistic management which are linked by material, service, financial and information flows. Proceedings presented in [8-11] are also oriented to dual-type structure of the system in terms of "services customer-transport enterprise" however the author [10] includes also service users into the graphic representation of the PPT logistics system model. Based on object decomposition, the author $[12,13]$ includes into the system structure (in capacity of system organizer and transport services customer) (i) the city Administration which is implementing the complex of main and auxiliary functions intended to satisfy the demands of the customers using PPT services and (ii) the transport enterprises providing passenger transportation services. At the same time, article [12] demonstrates presence of logistics flows in the system under research; at that, the main flows are represented by passenger flows whose unique feature consists in identicalness between flow-forming objects and users of logistics system services [12, p.289] which fact gives grounds to consider service users as one of the main logistics system elements. In our viewpoint, including of users into the model of the PPT logistics system is essentially important since it allows to take into account, on the one hand, customer centricity requirement and, on the other hand, nature of flow-related processes while managing the system under research

However, expanding of users demands to content and quality of PPT services and awareness of the role played by the public transport in the course of the city development requires modernization of classic approach to managing PPT as a logistics system. Basic principle in selecting the advanced form of organization of the city PPT system is the necessity to ensure harmonizing of interests of recipients of the PPT system development results to which we must refer:

- service users forming the set of "ideal" requirements to PPT Services;

- city (as an open socio-economic and naturaltechnological system) from the standpoint of which the level of transport system development functions as a factor promoting further evolution of city environment and contributing to city resources regeneration (Figure 1).

Development of logistics approach from the perspective of evolutionary economy provides possibilities to implement the aforesaid principle and this, from the viewpoint of the PPT system organization form, is associated with transition from qualifying it as logistic system to ecosystem having logistics management features. City PPT ecosystem under formation is inheriting the structure of logistics system supplemented by a number of elements satisfying top level requirements of the PPT users and of the city in whole.

Analysis of results (of ecosystems formation principles survey) presented in [2] and adaptation thereof to specific features of object under research enables us to identify its below listed elements: customer; transport enterprises; users of the city PPT system services; suppliers of material, human, financial resources; middlemen (including "digital" ones); alternative mobile systems; professional and public associations.

Demands pyramid of city as a socio-economic and natural-technological system

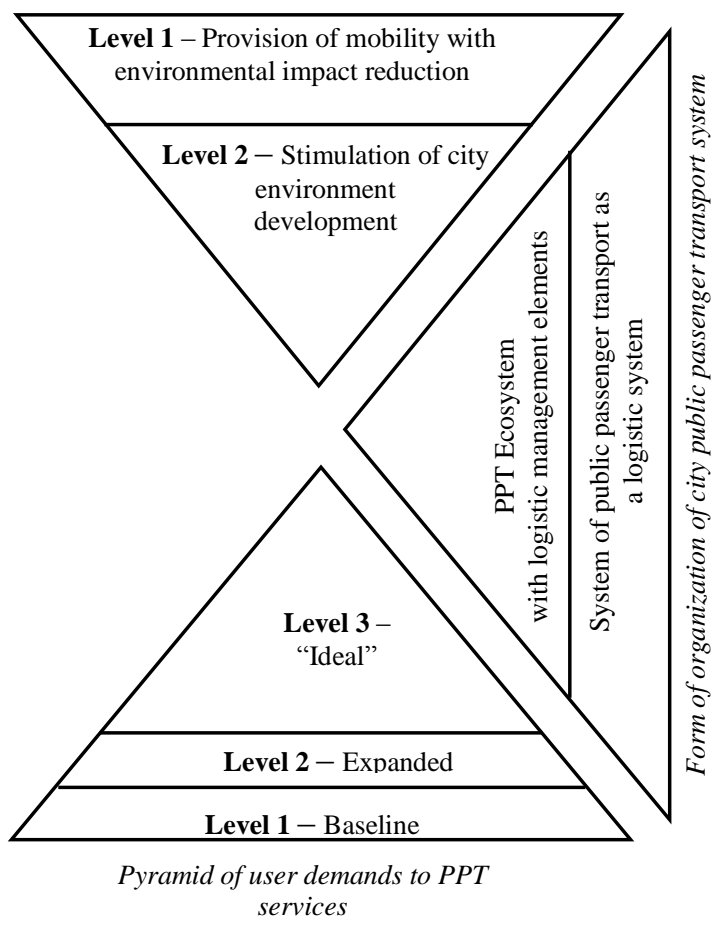

Fig.1. Potential of using ecosystem-based approach while selecting the forms of city public passenger transport organization system

At the same time, increasingly growing structural complicacy of system under investigation makes definition of its boundaries, which is first of all connected with definition of elements, included thereto, a crucial task.

Transition to the ecosystem-based PPT organization envisages profound reformation of the city transport system management which may cause considerable control loss risks.

\section{B. Principles of engineering of city public passenger transport systems}

"Logistics engineering" principle proceeds from Benjamin S. Blanchard's article entitled "Logistics engineering \& management", 1974 [16] in which he is proposing and alternative approach aiming to identify logistics as a complex of mechanisms providing efficient and cost-effective support to technical systems for their entire service life period.

Mentioning of logistics engineering in connection with city transport systems is frequently met in articles published by Journal of Traffic and Logistics Engineering [17] where it is referred to as "organization, designing and managing transport systems and flows".

Overall representation of "logistics engineering" notion was first done in [18]: "logistics engineering" - scientific and practical activities associated with execution of research, engineering, design, consulting and computational works intended to ensure optimized functioning of logistic systems and supply chains in the course of their entire life time cycle". The logistics system life time cycle is 
understood as uninterrupted process of forecasted evolutions of logistics system's statuses occurring in specified sequence [19].

Below listed are stages of the PPT logistic systems life cycle: formation, development, maturation, stagnation, modernization (re-engineering), liquidation. Examples of the PPT logistics system liquidation - (i) elimination of regional railways network in France in 1950-60th due to their poor profitability and transition to road transportation and (ii) elimination of tramway transport in a number of European cities which took place approximately at the same time.

Modernization of transport logistics systems is performed with the use of re-engineering: employment of new types of transport and transportation methods, new concepts and technologies providing interaction between the system participants, inter alia, with the use of cutting-edge digital technologies (so-called "digital transformation").

Structure of engineering of urban public passenger transport (UPPT) logistics transport systems includes: designing; controlling; optimization; re-engineering- Fig. 2 below.

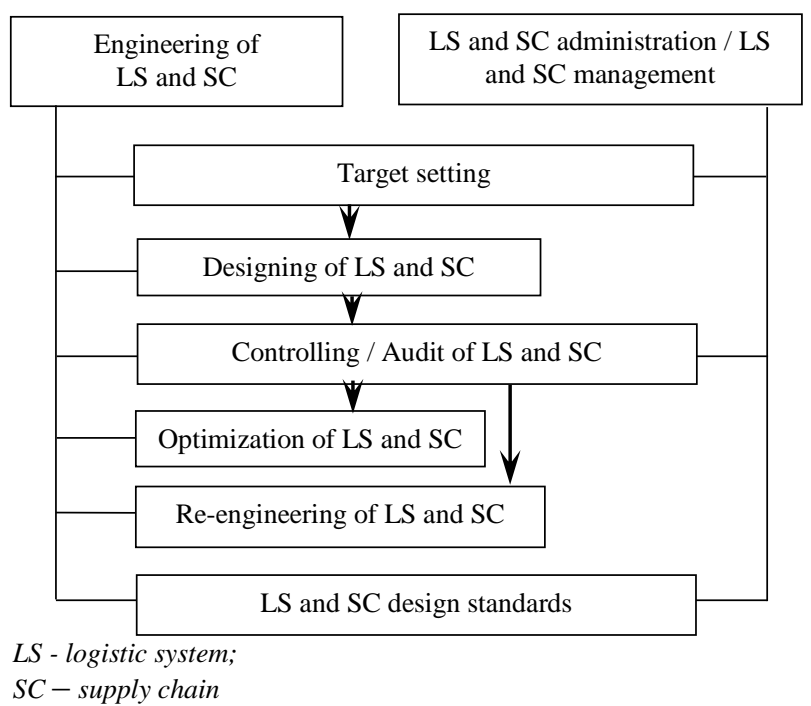

Fig.2. Structure of the city PPT engineering

Engineering is expected to interact with administration (logistics systems management) in a way to define targets, standards and key indicators of the UPPT logistics system development, furthermore, in terms of transition to ecosystem approach to UPPT systems formation and development.

In our opinion, main targets of the logistics systems engineering in terms of ecosystem aspect are:

- formation of the UPPT ecosystem;

- designing of passenger transport logistics systems which take into account specific features (structure ands characteristics) of the UPPT ecosystem;

- modelling (including imitation) of UPPT logistic systems;

- elaboration and implementation of system enabling the UPPT logistics system efficiency assessment;

- revealing of "weak points" and improvement of existing UPPT logistic systems (optimization and reengineering);
- preparation to elimination of UPPT logistics systems which lost their value for the ecosystem.

Implementation and development of the UPPT logistics systems engineering concept is intended to improve efficiency of managerial and design solutions in the sphere of the UPPT logistic systems formation and functioning at the expense of synergetic effect resulting from the combination of administering, designing, controlling and reengineering (optimizing) methodologies.

Recognition of the ecosystem aspect in the UPPT logistics systems engineering is designed to ensure longterm and well-balanced sustainable development of UPPT which is accounting for value-based aspect both for end users (passengers - residents of city or larger unit) and for entire ecosystem.

C. Value-based model of formation of the city PPT logistics systems

Typically, formation of logistics systems is based on recognition of principle of the cumulative logistics expenditures optimization. The ecosystem-based approach is assuming the necessity to take into account value-based aspect while forming the UPPT logistics system.

Value-based approach to logistics systems and supply chains formation which is integrating the ideas of cumulative logistics expenditures optimization and Michael Porter's value chain concept [20] was for the first time demonstrated in our article [21].

In order to improve efficiency of UPPT logistics systems in terms of the ecosystem-based aspect we propose (i) to take into account assessment of the added value (for each user and for the ecosystem in whole) which is created by each element of the UPPT logistics system and (ii) to compare it with expenses, risks, delays which are connected with functioning of the UPPT logistics system element while they are being designed.

It is possible to analyze expediency of any element (participant, middleman) integration into the UPPT system in the following way: if any element of the UPPT LS creates additional cost but fails to add value from the viewpoint of the end user and ecosystem in whole it is expected that such element should be, preferably, excluded from the system in the course of designing and re-engineering.

Elemental structure of value-based model of the UPPT logistics systems formation is shown in Fig. 3 below.

Using designations presented herein it is possible to reflect the process of "added value" and added expenses (costs, time and damage) formation in the logistics system:

- formation of additional cost in the logistics system:

$$
C_{B X}=P_{A X}+\sum_{i=1}^{N} \Delta_{i}^{p}
$$

- formation of "accumulated" time losses in the logistics system:

$$
T_{B X}=T_{A X}+\sum_{i=1}^{N} t_{i}
$$

- assessment of probable "accrued" damages in the UPPT logistics system: 


$$
D_{B X}=\sum_{i=1}^{N} \sum_{j=1}^{M} p_{i j} \cdot d_{i j}
$$

- formation of "added value" in the UPPT logistics system:

$$
Q_{B X}=Q_{A X}+\sum_{i=1}^{N} q_{i}
$$

The value-based model of UPPT logistics systems formation assumes comparison between added value and added expenses for each system element in order to exclude elements whose associated costs are either equivalent or exceeding the anticipated added value:

$$
\Delta q_{i ; i+1} \geq \Delta \Pi_{i ; i+1}, \text { where }
$$

$\Delta q_{i ; i+1}$ - increment of added user value;

\begin{tabular}{|c|c|c|c|}
\hline $\mathbf{A}$ & $I_{1}$ & $\mathbf{I}_{2}$ & $\mathbf{I}_{\mathbf{N}}$ \\
\hline \multirow{2}{*}{$\mathrm{Q}_{\mathrm{A}}$} & $+q_{1}$ & $+q_{2}$ & $+\mathrm{q}_{\mathrm{n}}$ \\
\hline & $+\Delta_{1}^{p}$ & $+\Delta_{2}{ }^{p}$ & $+\Delta_{N}^{p}$ \\
\hline $\begin{array}{c}\mathrm{rA}_{\mathrm{A}} \\
\mathrm{x}\end{array}$ & $\begin{array}{c}+\mathrm{t}_{1} \\
+\end{array}$ & $\begin{array}{c}+\mathrm{t}_{2} \\
+\end{array}$ & $\begin{array}{c}+t_{N} \\
+\end{array}$ \\
\hline
\end{tabular}

$\Delta \prod_{i ; i+1}$ - increment of added losses (added cost, time accrued, damages accrued).

$A$ - producer of baseline transport service - transport operations,

$B$ - end user (passenger);

$I$ - element of the UPPT logistics system / UPPT ecosystems, $(i=1 \div n)$;

$P_{A X}$ - baseline cost of transportation;

$\Delta i^{p}$ - increase on the base cost of transportation associated with functions of i-element of the UPPT logistics system;

$C_{B X}$ - final cost of transportation service for passenger and for the ecosystem in whole

$\mathrm{D}_{B X}-$ potential risk in the system

$p_{i j}$ - probability of risk situation $j(j=1 \div)$ due to functioning of $i$ element of the UPPT logistics system

$d_{i j}$ - anticipated damage caused by functioning of i-element of the UPPT logistics system

$T_{B}$-assessment of time losses;

$T_{A X}$ - baseline time;

$t_{i}$ - time of delays caused by functioning of i-element of the UPPT logistics system;

$Q_{B X}$-index of assessment of the cumulative summary transport service value for the user and for the ecosystem in whole;

$Q_{B X}$ - baseline assessment of the consumer value of transport service for user $B$ and for the ecosystem in whole;

$q_{i}$ - assessment of additional consumer value of the transport service for the user and for the ecosystem in whole achieved due to functioning of i-element of the UPPT logistics system.

Fig.3. Value-based model of formation of the city PPT logistics systems.

D. Model of assessment of expediency of transition to the ecosystem-based approach for the purpose of the city PPT logistics systems advancement

In our opinion, boundaries of expediency of the ecosystem-based approach employment for the purpose of UPPT logistics systems formation and development $-100 \%$ obtaining of targeted value parameters which could be achieved only through the use of conventional and logistics approaches to aforesaid systems formation - refer to Fig. 4 below.

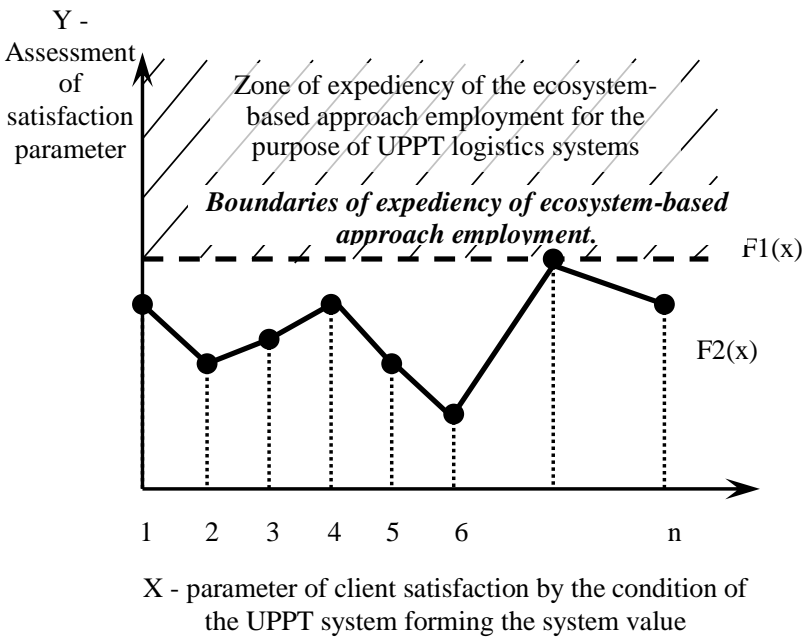

F1(x) - function characterizing the target value of quality parameters of the UPPT logistics system functioning assessment

F2(x) - function characterizing actual assessment of achievement of target values of quality parameters of the UPPT logistics system functioning assessment;

$x$ - order number of parameter of qualitative assessment of the UPPT logistics system functioning, $x=1 \div n$

Fig.4. Model of assessment of expediency of transition to the ecosystembased approach for the purpose of UPPT logistics systems advancement

Taking the aforesaid and the aforementioned designations (Fig. 4) into account, we can formulate the following condition enabling us to evaluate expediency of transition to the ecosystem-based approach in UPPT logistics systems engineering:

$$
\int_{1}^{n} F 1(x) d x-\int_{1}^{n} F 2(x) d x \leq 0
$$

Appearance of zero or negative values in the presented expression will accordingly represent achievement or excess of achieved parameters of qualitative assessment of the UPPT logistics system functioning in comparison with the target values system.

Aforementioned model may be also represented in discrete formulation as referencing of sums of achieved actual and target values of parameters of qualitative assessment of the UPPT logistics system functioning:

$$
\sum_{i=1}^{n} y_{i}^{1} \leq \sum_{i=1}^{n} y_{i}^{2}
$$

Where $\boldsymbol{y}_{\boldsymbol{i}}^{\mathbf{1}}$ - target value of $i$ - parameter of qualitative assessment of the UPPT logistics system functioning;

$\boldsymbol{y}_{i}^{2}$-actual value of $i$ - parameter of qualitative assessment of the UPPT logistics system functioning.

We can also consider achievement of the target value for each individual parameter:

$$
y_{i}^{1} \leq y_{i}^{2}
$$




\section{RESULTS}

The study conducted enabled us to perform systematization of users requirements towards city public passenger transport services as a result of which we identified the following groups:

Level 1 -Baseline requirements: satisfaction of transfer demand, trip safety;

Level 2 - Expanded requirements: accessibility (spatial; price affordability); timekeeping; speed of transfer; comfort (transport vehicle cleanness; comfortable climatic conditions etc.);

Level 3 - "Ideal" requirements: unified information environment and information support during transfer; variability of routes accompanied by the possibility to use integrated transportation solutions (by types of the UPPT, time table etc.); solving of "last mile" problem; raise requirements towards transportation comfort; environmental friendliness.

Degree of aforesaid requirements satisfaction demonstrates, in our opinion, the importance of the value of index of assessment of cumulative summary value of PPT services for users and this fact, in its turn, allows to dovetail requirements satisfaction with particular element of the UPPT logistics system element (Table 1).

TABLE I DISTRIBUTION OF ADDED VALUE FORMATION CONDITIONS (FROM THE STAND POINT OF SERVICE USERS) AMONG THE ELEMENTS OF THE PUBLIC PASSENGER TRANSPORT ECOSYSTEM

\begin{tabular}{|c|c|}
\hline Carrier & Service customer \\
\hline \multicolumn{2}{|c|}{ Level 2 - Expanded requirements: } \\
\hline \multicolumn{2}{|c|}{ Accessibility } \\
\hline $\begin{array}{l}\text { - provision of required vehicle stock } \\
\text { quantity }\end{array}$ & $\begin{array}{l}\text { - development and optimization } \\
\text { of route network; } \\
\text { - verification of halting points } \\
\text { arrangement }\end{array}$ \\
\hline \multicolumn{2}{|c|}{ Integrated safety and security } \\
\hline $\begin{array}{l}\text { - availability of vehicle stock (VS) } \\
\text { ensuring additional safety } \\
\text { requirements; } \\
\text { - involvement of high-qualification } \\
\text { personnel (drivers); } \\
\text { - organization of transportation } \\
\text { process preparation (organization of } \\
\text { (i) technical maintenance and repair } \\
\text { of transport vehicles (TV), (ii) pre- } \\
\text { trip medical check-up and } \\
\text { instructing of personnel (drivers)) }\end{array}$ & $\begin{array}{l}\text { - systematization of applicable } \\
\text { within existing legislation and } \\
\text { development of additional } \\
\text { requirements to vehicle stock } \\
\text { and carrier personnel aiming to } \\
\text { ensure integrated safety and } \\
\text { security of passengers in the } \\
\text { course of service acceptance }\end{array}$ \\
\hline \multicolumn{2}{|c|}{ Speed of transfer (including TV waiting time spent at halting points) } \\
\hline $\begin{array}{l}\text { - involvement of high-qualification } \\
\text { personnel (drivers); }\end{array}$ & $\begin{array}{l}\text { - verification of traffic with } \\
\text { reference to routes established; } \\
\text { - creation of proper conditions } \\
\text { ensuring observance of the TV } \\
\text { traffic schedule (in particular, } \\
\text { agreeing of traffic arrangement } \\
\text { with respective authorities etc.) }\end{array}$ \\
\hline \multicolumn{2}{|c|}{ Comfort } \\
\hline $\begin{array}{l}\text { - availability of vehicle stock } \\
\text { capable to ensure comfort during } \\
\text { transfer; } \\
\text { - availability of additional } \\
\text { equipment and devices ensuring } \\
\text { comfortable transfer; } \\
\text { - characteristics of the vehicle stock } \\
\text { (years of service life, technical } \\
\text { condition); } \\
\text { - organization of technical } \\
\text { inspection, maintenance (DM-daily } \\
\text { maintenance) and repair of the }\end{array}$ & $\begin{array}{l}\text { - elaboration of transfer } \\
\text { comfort requirements within } \\
\text { city public passenger transport } \\
\text { system; } \\
\text { - elaboration of mechanisms } \\
\text { ensuring compensation to } \\
\text { carriers in view of additional } \\
\text { expenses associated with } \\
\text { transfer comfort provision }\end{array}$ \\
\hline
\end{tabular}

\begin{tabular}{|l|l|}
\hline $\begin{array}{l}\text { vehicle stock; } \\
\text { - involvement of high-qualification } \\
\text { personnel; }\end{array}$ & \\
- availability of corporate quality \\
standard;
\end{tabular}

Let us consider, for instance, the level of users' satisfaction by PPT services referring to various indices (Figures 5-6). Results have been obtained by means of questioning survey. The questioning survey covered 51 persons of various social and age categories using the public passenger transport of the city of Saint Petersburg. Indices were selected with account to affiliation to level 2 "Expanded requirements" whose anticipated (reference) values achievement demonstrates the city PPT logistics system readiness for transition to the ecosystem (refer to Fig.1).

In whole, analysis of values obtained shows that the city PPT is not ready for fullfledged transition to the ecosystembased organization principle; at present, it is recommended to provide evolutionary development within the framework of the PPT logistics system with implementation of ecosystem-based elements in terms of extension of the number of transport services providers and in terms of their activities management methods. 


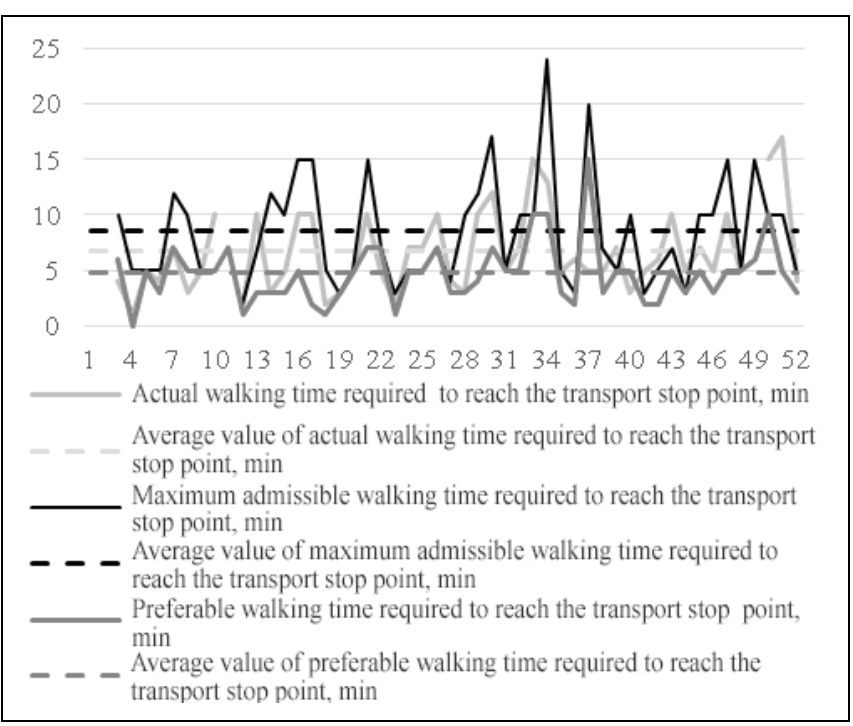

Fig.5. Assessment of passenger-perceivable value of transport services with reference to "Accessibility" index

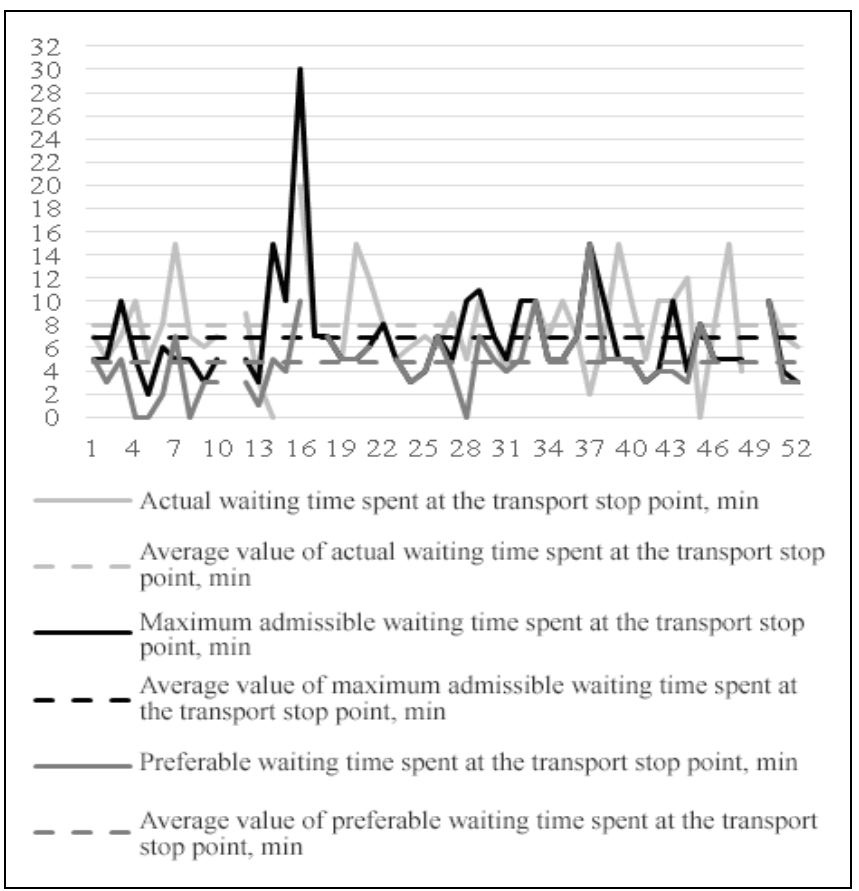

Fig.6. Assessment of passenger-perceivable value of transport services with reference to "Speed of transfer" index

\section{DISCUSSION}

Extended results of research carried out to evaluate user satisfaction level make it possible to conclude as follows:

- operability of the model of assessment of expediency of transition to the ecosystem-based approach for advancement of the city PPT logistics systems has been proven for well-examined (in terms of revealing the transportation service requirements) group of users passengers using the city PPT system; meanwhile, formulation of indices reflecting the process of added value formation from the viewpoint of the city requires additional research;

- proposed model and methods of assessment of user demands satisfaction connected therewith allows (i) to substantiate solutions relating to re-engineering of the city PPT system from the standpoint of the ecosystem-based approach when values of parameters of client satisfaction by the UPPT system condition are overrunning the set up boundary of its usage and forming the system value and (ii) to establish directions of improving the PPT logistics system where conditions of transition to ecosystem are not observed;

- while solving the problems of definition of structure of the city PPT ecosystem under formation attention should be paid to the issue associated with management/selfmanagement (self-organization) of the system. Obviously, it is necessary to point out "manageable" block and block (package) of elements functioning on the basis of alternative conditions (self-organization, in particular). Role of "focusing company" maintaining control within the system under consideration shall be assigned to the city Administration.

\section{CONCLUSIONS}

Further development of tool enabling engineering of the city PPT system is, in our opinion, associated with research which should be done in the following directions:

- formation of value-based assessment system from the standpoint of the city being a socio-economic and naturaltechnological system where public transport is considered to be the factor of sustainable development of the city environment;

- concretization of assessment of added expenses associated with the city PPT logistics system development in order to substantiate solutions regarding selection of logistics system development scenarios;

- elaboration of synthetic approach towards formation of quantitative parameters of functions characterizing the target value and actual assessment of achieving the target values of qualitative parameters of assessment of the UPPT logistics system functioning.

\section{REFERENCES}

[1] Zhuk A.Ye. "Development of large city public passenger transport logistics system based on evolutionary economy principles", Logistics and supply chains management: collection of scientific articles, Issue 2 (15), p.80-87, 2018.

[2] Doroshenko S.V. "Business ecosystem in modern socio-economic research", Economic theory magazine. No. 4. 2017. p.212-221.

[3] Veselov K. S., Nazarov M. G., Shirokova D. V. "Survey of regional business ecosystem development issues (with reference to Nishny Novgorod region)", Regional economy: theory and practice, No. 7, p. 76-88, 2016.

[4] Dubina I. N., Kozhevina O. V., Chub A. A. "Innovative-business ecosystems as a factor of regional sustainability", Economic analysis: theory and practice. No. 4 (451), p. 4-19, 2016

[5] Durst S., Poutanen P. "Success factors of innovation ecosystems: Initial insights from a literature review", CO-CREATE 2013: The Boundary-Crossing Conference on Co-Design in Innovation, Aalto University, pp. 27-38, 2013.

[6] Tian X. H., Nie Q. K. "On Model Construction of Enterprises' Interactive Relationship from the Perspective of Business Ecosystem", South China Journal of Economics, No. 4, pp. 50-57, 2006.

[7] "Logistics: public passenger transport" / under the editorship of L.B. Mirotina. Moscow: Examen, 2003. p. 224.

[8] Shabanov A.V. "Regional logistics systems of public transport: methodology of formation and management mechanism". Rostov on 
Don.: Publishing House of North Caucasian scientific Center of Higher School, 2001.

[9] Tregubov V.N. "Methodological aspects of urban public passenger transport logistics system management based on synchronization concept", Messenger of Saratov state technical University. V.4, No. 2(50), p.167-175, 2010

[10] Malchikova A.G. "Organization of logistics flows within the system of urban passenger transportation": dissertation in candidacy for the degree of candidate of economic sciences, Saint Petersburg: Saint Petersburg State University of Economics, 2000

[11] Zolotushkina Zh.A. "Designing and functioning of regional passenger transportation logistics systems on the basis of adaptive management models": dissertation in candidacy for the degree of candidate of economic sciences Saratov: Saratov State Technical University named after Yu.A. Gagarin, 2015.

[12] Shulzhenko T.G. "Use of logistics conceptual provisions in order to ensure quality of public passenger transport system services in condition of megapolis", Logistics potential of Saint Petersburg in innovative economy formation: Proceedings of International research to practice conference. December 1-2, 2016, p.289-293.

[13] Shulzhenko T.G. "Applied aspects of transport services quality control within the logistics system of large city public passenger transport system". Business. Education. Justice. Messenger of Volgograd institute of business. No. 4 (41), p.87-99, 2017
[14] Lepekhin, A., Borremans, A., Iliashenko, O. Design and implementation of IT services as part of the "smart City" concept (2018) 170, 01029.

[15] Kankovskaya, A., Kalinina, O., Ilin, I. Economics of transport and sustainable development: Problems of high education in Russia (2018) 239, 08008.

[16] Blanchard, B. S. «Logistics and Engineering Management», PrenticeHall Inc, Englewood Cliffs NJ, 1974.

[17] www.jtle.net

[18] Badokin O.V. "Engineering of logistics systems and supply chains; idea and prospects". "Logistics: modern tendencies of development", Proceedings of XVIII international research to practice conference, $\mathrm{p}$. 26-28, 2014.

[19] Volodina Ye. V. "Formation and life cycle of logistics system development in competitive environment of regional food products market": dissertation in candidacy for the degree of candidate of economic sciences, 2007.

[20] Michael E. Porter. "Competitive Advantage: Creating and Sustaining Superior Performance". Free Press, 557 p., 1985.

[21] Badokin O.V. "Value-based audit in supply chains design". Logistics and trade policies: collection of scientific papers, Issue 1 (12), Saint Petersburg, Saint Petersburg State University of Economics, p.25-28, 2014 